\title{
Artigos
}

\section{A PULSÃO DE TEATRALIDADE E A SOBREVIVÊNCIA DO TEATRO NA ATUALIDADE}

THE INSTINCT OF THEATRICALITY AND THE SURVIVAL OF THE THEATRE IN CONTEMPORANEITY

LA PULSIÓN DE TEATRALIDAD Y LA SUPERVIVENCIA DEL TEATRO EN LA ACTUALIDAD

\author{
Elen de Medeiros \\ Matheus Borelli dos Santos
}

Elen de Medeiros

Professora de literatura e teatro na Faculdade de Letras da Universidade Federal de Minas Gerais.

Matheus Borelli dos Santos

Graduando em artes cênicas na Universidade Federal de Ouro Preto. 


\section{Resumo}

Este artigo busca, por meio de uma leitura de $O$ teatro é necessário?, de Denis Guénoun, aproximar as ideias abordadas pelo autor ao conceito de "pulsão de ficção", forjado por Suzi Frankl Sperper, em uma tentativa de refletir acerca das motivações do espectador contemporâneo ao buscar uma obra teatral. Esse pensamento, apoiado na noção da tríplice mimese, de Paul Ricoeur, irá levantar possibilidades que investigam como um espaço institucionalizado pode proporcionar terreno fértil para o cultivo dessa necessidade humana pela ficcionalização.

Palavras-chave: Contemporaneidade, Espectador, Imaginário, Jogador.

\section{Abstract}

This article aims, through the reading of Is theatre necessary?, by Denis Guenoun, to approximate the ideas dealt by the author to the concept of "instinct of fiction", forged by Suzi Frankl Sperper, in an attempt to reflect on the motivations of the contemporary spectator when looking for a theatre play. This thought, supported by the concept of triple mimesis, by Paul Ricoeur, will investigate how an institutionalized space can provide a fertile ground to cultivate this human need for fictionalization.

Keywords: Contemporaneity, Imaginary, Spectator, Player.

\section{Resumen}

Mediante la lectura de ¿El teatro es necesario?, de Denis Guénoun, este artículo pretende acercar las ideas abordadas por este autor al concepto de Pulsión de ficción, forjado por Suzi Frankl Sperber, en un intento de reflexionar sobre las motivaciones del espectador contemporáneo al buscar una obra de teatro. Este pensamiento, apoyado en el concepto de la triple mimesis, de Paul Ricoeur, sugiere posibilidades que investigan cómo un espacio institucionalizado puede proporcionar un terreno fértil para el cultivo de esta necesidad humana de ficcionalización.

Palabras clave: Contemporaneidad, Imaginário, Espectador, Jugador.

Tudo está pronto para o início do ensaio. Os atores reunidos no palco apenas aguardam a chegada do Diretor e da Primeira Atriz. Assim que ambos chegam, começam a ensaiar o espetáculo $O$ jogo dos papéis. $O$ Primeiro Ator, antes mesmo que se desse o pontapé inicial, zomba de algo no texto 
que julgava ser "ridículo": foi pouco para que se desenrolasse toda a querela do Diretor sobre a escassa produção dramatúrgica de qualidade, que deixa poucas opções para o trabalho. É quando chegam, de supetão, o porteiro do local acompanhado por seis personagens que reivindicam representação. $O$ Pai, a Mãe, a Enteada, o Filho, o Rapazinho e a Menina clamam por um autor que dê vida ao seu drama. Eles expõem sua história ao diretor e aos atores, para persuadi-los de que merecem ser encenados. Mas quando enfim conseguem convencê-los, se chocam com o incontestável fato de que a representação teatral de seu drama jamais seria equivalente àquilo que viveram, jamais se igualaria à tragédia de suas vidas. Desde os atores que tanto distam de sua real aparência e essência até o cenário, a mobília... nada é como deveria. A realidade do palco não é suficiente para representar a sua ficção.

Esse trecho, um breve resumo de Seis personagens à procura de um autor, de Luigi Pirandello, revela a crise enfrentada pelo drama no início da década de 1920 e coloca em tensão uma questão fundamental do teatro: os níveis de representação entre ficção e realidade.

Há um século de nós, o autor se pergunta o que, basicamente, nos perguntaremos neste artigo: qual é a serventia do teatro? Interessa-nos refletir sobre o que o teatro proporciona, enquanto arte que acontece e é assistida em tempo real, ou seja, que só existe no contato imediato com o espectador.

Assim, o texto de Pirandello nos serve como catapulta para refletirmos sobre o que, na arte do teatro, ainda se faz necessário de modo a mantê-lo vivo até os dias de hoje e sobre de que modo a ficção teatral se apresenta ao espectador contemporâneo. Para tanto, serão discutidos e entremeados o conceito de pulsão de ficção, proposto por Suzi Frankl Sperber e o debate aventado por Denis Guénoun, sobre a necessidade do teatro na atualidade, em seu livro $O$ teatro é necessário?

Pensa-se aqui, pretensiosamente, que há algum componente da arte teatral que, devido à interação imediata proposta por ela, desperta em atores e espectadores um possível sentimento de conexão com traços arquetípicos do ser humano e que, talvez, esse sentimento seja o grande alicerce da longevidade do teatro.

No passar de sua existência, o teatro viveu diversos momentos. Assim, um breve caminho será percorrido para alcançar o cerne da seguinte reflexão: 
o que garante, hoje, a sobrevivência dessa arte, com toda a sua atual e cumulativa pluralidade, a partir da qual tentaremos encontrar um denominador comum que justifique a necessidade do teatro.

Nas palavras de Guénoun, necessidade é o nome da brutalidade de um chamado da vida, de modo que esta prevaleça sobre a morte (GUÉNOUN, 2012, p. 16). Ora, ao aproximar a necessidade do teatro a um chamado brutal, cuja rejeição pressupõe um risco de morte, o autor eleva a simples necessidade àquilo que seria uma necessidade imperiosa (SPERBER, 2002, p. 282), aproximando-a do complexo conceito de pulsão, analisado segundo a perspectiva de Sperber.

No livro Fic ção e razão: uma retomada das formas simples, a professora doutora Suzi Frankl Sperber (2009b) investiga, por meio da convergência de pensamentos psicanalíticos, linguísticos e antropológicos, a necessidade humana de elaborar ficções. Para além do livro citado, em entrevistas e artigos que serão utilizados na nossa análise, Sperber discorre sobre o tema, nos guiando por um caminho que levará ao cunho do termo pulsão de ficção.

As pesquisas de Sperber (2002) se iniciam por meio da compreensão da oralidade e dos processos de aquisição da linguagem enquanto procedimento de atribuição de significados ao mundo. Amparada por estudos de Claudia Lemos (UNICAMP), Sperber (2002, p. 262) relata que "a criança constrói suas primeiras narrativas por volta dos três anos de idade, sendo esta a primeira manifestação estruturada e completa da fala infantil", concluindo, na sequência, que "a sua primeira fala não utilitária, pertenceria, pois, ao nível do imaginário" (Ibid., p. 263). A partir de tal constatação, surge a questão desencadeadora do pensamento da autora, que entende que, embora a primeira manifestação oral estruturada da linguagem ocorra próxima aos três anos de idade, o imaginário se manifesta muito antes disso, é inato, segundo Lacan (apud Serber 2002).

Ora, se o imaginário é anterior a esse processo de atribuição de significados ao mundo, não poderia ser ele um dos estruturadores de tal processo? Sperber (2002), a partir de investigações das raízes do imaginário, chega ao jogo fort-da, analisado por Freud (1920) em Além do princípio do prazer. O jogo consiste em uma aparente brincadeira realizada pelo neto de Freud - criança de um ano e meio de idade, portanto, ainda distante da fase de 
enunciação estruturada da linguagem - quando da partida de sua mãe, em que o pequeno puxava e empurrava um carretel preso por um barbante emitindo alguns sons, interpretados pelo avô como as palavras fort (ou "foi-se") para quando o carretel se afastava e da (ou "voltou") para quando o carretel se reaproximava. A criança não chorava ao se despedir da mãe, mas após a separação lançava mão desse recurso lúdico.

Freud, supondo que o jogo fazia referência ao evento vivido pela criança, elaborou sua hipótese de que o ser humano, além de ser movido por uma busca de prazer e uma evitação do desprazer, tem a necessidade de elaborar, organizando de forma inteligível, sentimentos negativos, como a decepção, a dor, a perda, o sofrimento. Sperber (2002) enxerga algo mais nesse evento: entende que o jogo fort-da permite que o evento vivido seja elaborado pela criança a partir de um traço específico fundamental: o seu caráter ficcional. Ou seja, é a qualidade de ação cênica ficcional do jogo que, como uma lente entre o sujeito e o evento, permite que este seja elaborado e revestido de novo significado.

A pulsão de ficção é composta por imaginário, simbolização e efabulação, que seria a criação de narrativas investidas de valor simbólico (SPERBER, 2009a, p. 7). A repetição dessa narrativa é parte fundamental de todo esse sistema, posto que ela é o principal operário responsável por construir, por meio dos tijolos da ficção, a reelaboração do evento vivido, fazendo da efabulação uma espécie de ritual sagrado, porque está inserida em uma temporalidade cíclica.

A efabulação se caracterizaria também como uma espécie de incentivadora do ser humano diante do evento, a partir do momento em que o coloca no lugar de agente e não mais apenas receptor da ação: a criança que antes chorava passivamente em protesto pela partida da mãe e depois se acalmava em aceitação ao adeus, agora reage colocando-se como narrador ativo de um jogo cênico que a impulsiona rumo a um novo nível de compreensão sobre a separação.

Esse exercício de aproximações e afastamentos do mundo e de si, por meio da ficcionalização, compreende a busca de elaboração dos sentimentos negativos, que é arquetípica, e "corresponderia a uma necessidade fundamental do ser humano, necessidade configurada no esforço (pulsão) perma- 
nente de reestabelecimento de equilíbrio interno" (SPERBER, 2002, p. 282), concedendo à ficção a condição de pulsão que seria, então, inata a todo e qualquer ser humano.

Definido o conceito, Sperber (2002, p. 284) refletirá sobre o que aciona ou desperta a nossa pulsão de ficção. É então que chega à conclusão de que "a mais profunda necessidade de expressão do ser humano corresponderia à expressão de momentos diferentes de iniciação, de confronto" e que, portanto, a pulsão de ficção nasce de situações-limite - que são, para Karl Jaspers, o pecado, a solidão, a morte, a frustração - e às quais é somado, pela própria autora, o ingresso no mundo de risco, portanto do medo (SPERBER, 2009a, p. 11).

Assim, refletiremos se existe a possibilidade de uma situação de equilíbrio e tranquilidade ao despertar a pulsão de ficção. E se essa poderia ser ativada por uma efabulação exógena. Para assim discutir sobre de que modo participar e/ou assistir a um espetáculo teatral poderiam ser despertadores da pulsão de ficção, de sorte que esteja garantida, por seu caráter ficcional, a existência do teatro enquanto arte. O que garantiria que o teatro não fosse, todavia, sobreposto por artes similares como o cinema e a TV? É nesse momento que trazemos Denis Guénoun ao debate.

O teatro é necessário? A partir dessa questão, Guénoun (2012) se vale de análises feitas por diversos pensadores em diferentes épocas para debater sobre os significados que o teatro foi adquirindo ao longo do tempo e que asseguraram sua longevidade.

A princípio, no entanto, para compreender os caminhos dessa investigação, precisamos nos ater ao ponto fulcral da pesquisa de Guénoun: o entendimento de que "o teatro não é uma atividade, mas duas. Atividade de fazer e atividade de ver" e de que "a especificidade do teatro diz respeito ao fato de que, nele, as duas atividades são indissociáveis e 'o teatro' só existe com a condição de que ambas se deem simultaneamente" (Ibid., p. 14).

Sabido isto, o autor nos leva por uma caminhada em que reflete sobre a necessidade do teatro em diferentes momentos históricos. De Aristóteles a Stanislavski, passando por Diderot e por outros pensadores, Guénoun nos encaminha ao século XX analisando como e por que o ato de assistir a e fazer teatro se fazia relevante. É então, que alcançamos um esquema de identificação proposto por Freud, em Personagens psicopáticos na cena: 
O espectador experimenta (fora do teatro), uma série de insatisfações: vive pouquíssimas coisas, nada de importante acontece com ele, teve que renunciar a sua ambição de estar no centro do universo. Como reação, ele quer sentir, agir, em resumo, ser um herói. E o teatro coloca isto ao seu alcance, por meio da identificação: pela identificação. (GUÉNOUN, 2012, p. 79, grifos do autor)

A identificação que permite esta recentralização do espectador no lugar de herói só se torna possível na medida em que produto, segundo Guénoun, de uma identificação anterior: identificação do representante com o representado e do público com a massa condensada que é o espectador, ambos entidades fictícias, portanto integrantes do campo do imaginário teatral, que dialogariam entre si. E é a garantia de segurança da realidade que possibilita a identificação em âmbito ficcional, ou seja, é a segurança do espectador sentado na poltrona, a certeza de que ele está isento dos sofrimentos da cena, que permitem que ele se identifique com ela.

Alcança-se, assim, o seguinte esquema de identificações: identificação do ator com o personagem, identificação do público com a entidade o espectador e identificação, no campo do imaginário, de o espectador com o personagem, formulando um sistema similar ao apresentado na Figura 1, ilustração proposta Guénoun (2012):

Figura 1 - Ilustração encontrada em O teatro é necessário?, de Guénoun

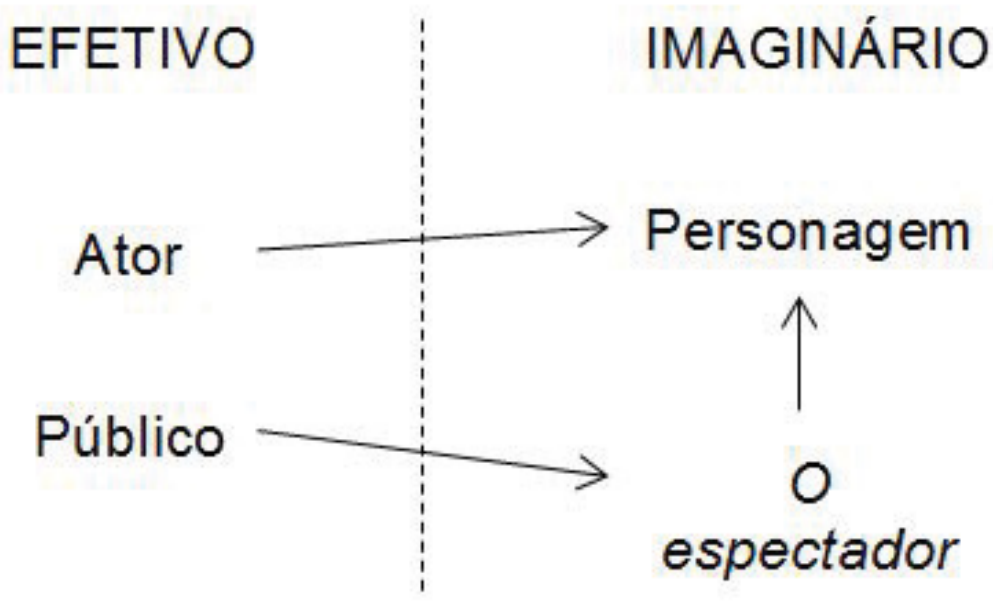

A figura revela que a potência do teatro, no início do século $X X$, repousa sobre sua configuração assumidamente imaginária, de modo que, como nos 
diz Guénoun (2012, p. 94, grifos do autor), "a irrealidade do teatro se tornou sua potência, o regime determinado de sua constituição".

É, então, sob o regime da imagem e do imaginário, que o teatro depara com sua maior ameaça contemporânea: consta, ainda do século XX, o advento do cinema. Como poderia um teatro baseado no imaginário concorrer com 0 cinematógrafo, que outorga à imagem uma existência efetiva, literal?

O cinema, ao que parece, tomou do teatro o seu motivo de ser:

As imagens do cinematógrafo tornam-se, então, imagens efetivas, imagens de direito, que proporcionam ao imaginário sua ex-sistência apropriada, a exteriorização que lhe convém, relegando todas as outras espécies de imagem à situação de "imagens" por metáfora. (GUÉNOUN, 2012, p. 102)

Imagem, segundo Guénoun (2012), não é ficção. Logo, o caráter ficcional do teatro não the confere o estatuto de imagem, isso porque a palavra imagem parece ter, com o surgimento do cinema, descoberto seu real significado: o de um atestado de presença pregressa. Como a fotografia e o cinema partem de um mesmo princípio imagético, o autor recorre a Barthes em seu ensaio sobre a fotografia, A câmara clara, para nos explicar um pouco do que se passa a entender por imagem nesse contexto:

Chamo de "referente fotográfico" [...] a coisa necessariamente real que foi colocada diante da objetiva, sem a qual não haveria fotografia. [...] A foto é literalmente uma emanação do referente. [...] toda fotografia é um certificado de presença. [...] na fotografia jamais posso negar que a coisa esteve lá. Há dupla posição conjunta: de realidade e de passado [...] o que vejo [...] é o real no estado passado: a só um tempo o passado e o real. (BARTHES apud GUÉNOUN, 2012, p. 104-105)

A característica cinética do cinema é o que o diferencia da fotografia. É isso o que o faz não apenas uma simples imagem, mas concretizador da imaginação: onde a imagem se produz e se move. Assim, o cinema extraiu do teatro seu âmbito imaginário e, com ele, todo o processo de identificação, situado no campo da imaginação.

O teatro, agora desmembrado entre o efetivo e o imaginário, isto é, entre o jogo prático de ação cênica e a imaginação, viu-se capenga. Para Guénoun 
(2012, p 110), "O imaginário (teatral) desertou o teatro, por ter assumido sua real independência". O que resta então ao teatro de hoje? Como se estrutura a necessidade do teatro em nossos tempos?

Segundo o autor, uma coisa é certa: se o teatro, contrário à sua possível caducidade, ainda sobrevive, é porque algo em sua atual conjuntura se faz necessário. O que seria, então? Ora, se o que resta ao teatro, desprovido do seu caráter imaginário, é o jogo de ação cênica, só pode ser sobre ele que se deposita a atual necessidade do teatro.

Dessa forma, o autor reflete sobre como a necessidade do teatro se configura, contemporaneamente, como necessidade de jogo. E, com ele, retoma conceitos como os de Aristóteles, que legavam ao teatro a primazia da ação:

O jogo será, portanto, o campo da ação teatral, o que não suprime o personagem [...] mas a ordena segundo uma lógica diferente da lógica identificadora [...]. O jogo agora é uma práxis na medida em que, mesmo que ele produza surtos de identificação (e produz, com certeza), mesmo que ele coloque em movimento personificações imaginárias, não são estas figurações que o instituem e o movem, mas sua auto-exposição como existência em cena. (Ibid., p. 136)

A ação do jogo aqui, no entanto, não se caracteriza como mimética, no sentido aristotélico, por não pretender uma aglutinação de representante e representado. Mas antes, se aproxima de uma cisão a tal ponto que chegue, talvez, a libertar o representante da necessidade de um representado, ou seja, que faça o ator independente do personagem fictício. $O$ teatro contemporâneo busca uma espécie de autossuficiência, que o faça necessário pelo simples fato de ser teatro. Pretende que o espectador vá "ao teatro com a intenção de que ali lhe apresentem uma operação de teatralização" (Ibid., p. 139).

Assim, qualquer um que vai ao teatro o faz com vistas ao jogo. O jogo é o atrativo tanto para quem age quanto para quem assiste. $E$ todo espectador contemporâneo é um jogador em potencial e por isso se identifica, não no âmbito do imaginário, mas no âmbito do real com ator em cena.

Afinal, percebemos um teatro almejante de um posto que lhe garanta a existência por ser necessário enquanto acontecimento teatral. $O$ teatro, agora, se vincula não mais ao imaginário, mas ao poético e seu feito teatral embebido de poesia. 
Pensá-lo assim, como necessidade absoluta nos leva a pensar que possa ser sua necessidade, também, algo mais, talvez necessidade inata e imperiosa, talvez uma necessidade pulsional. Desse modo, aventamos a possibilidade de que a necessidade do teatro se sonha pulsão de teatralidade. O que, portanto, nos levaria a um belíssimo encontro entre os dois conceitos abordados até agora neste artigo.

Se o teatro contemporâneo estabelece, segundo Guénoun (2012), pontes com os conceitos aristotélicos da Poética, a partir da noção de hegemonia da ação, nada mais justo que buscarmos em Aristóteles os princípios para a elaboração da nossa reflexão.

Partimos, então, para realizar esse encontro, de um princípio básico: Aristóteles considera que o ser humano tem uma tendência natural de representar e de se aprazer com a representação, o que nós nivelamos à tendência de efabulação, inscrita na pulsão de ficção, da qual nos fala Sperber (2002). A representação, afinal, pode ser também considerada uma espécie de narrativa investida de valor simbólico.

Também nos valemos do filósofo grego para chegar à conclusão, respondendo à pergunta que nos fizemos anteriormente, de que a pulsão de ficção pode ser ativada a partir da recepção de uma efabulação exógena. Ou seja, na medida em que o testemunho da prática teatral possibilita uma teoria, possibilita também a elaboração, por meio da concessão de sentido, do evento cênico assistido e, por silogismo, de possíveis eventos vividos por aquele que vê. Para Guénoun (2012, p. 27), "aquele que vê, raciocina". Logo, deduzimos que o prazer do conhecimento gerado pelo testemunho do evento teatral, está relacionado a um prazer de permitir, por meio de um jogo de efabulação de outrem, se colocar em contato com a necessidade própria de todo espectador (e todo ser humano) de efabular.

Assim, pensamos em um possível esquema de identificação em que, sim, os espectadores se identificam com os atores, por seu emprego de ação e de jogo. Mas se identificam também com o ser humano que, como eles, possui um latente desejo pela ficção; contudo, diferente deles, dá vazão a esse sentimento. É esse o caminho que levaria à nobreza do exercício teatral, portanto é esse caminho que faz com que as pessoas busquem assistir a teatro, a teatralidade, e o fazer teatro, o glamour da vida teatral. 
Em Tempo e narrativa, Paul Ricoeur (1994) nos leva a um aprofundamento do conceito de mímesis aristotélico, arquitetando aquilo que ele chamará $A$ tríplice mimese. Por meio desse conceito, Ricoeur nos levará por um caminho em que explica as três etapas da construção da mimese: desse modo, temos mimese // como a construção narrativa em si, compreendendo aquilo que entenderíamos como a essência da ficção, seu cerne. A mimese I e a mimese III seriam o entorno desse processo. A mimese I é o ponto de partida para a construção da mimese II, ou seja, o alicerce da construção da narrativa ficcional. A mimese III caracteriza a chegada da narrativa ficcional ao seu leitor e carrega todas as implicações de reconfiguração que a narrativa tende a ter a partir daí.

Damo-nos aqui o direito de transferir tais pressupostos ricoeurianos, elaborados com vistas à literatura, para a análise do evento teatral contemporâneo. Pensando na lógica de Guénoun, a ação efetiva é a linha axial a partir da qual de ramifica a teatralidade atualmente. Ora, se como relata Ricoeur (1994, p. 89) na mimese $I$, "agir é fazer coincidir o que um agente pode fazer - a título de 'ação de base' - e o que ele sabe, sem observação, o que é capaz de fazer," podemos compreender essa primeira camada mimética como já investida de valor ficcional, ainda que não aprofundado como deve ser na segunda camada mimética, que alinharemos aqui com a poética teatral, citada por Guénoun (2012). E se, de acordo com a mimese III, "o que é comunicado [...] é, para além do sentido de uma obra, o mundo que ela projeta e que constitui seu horizonte" e "o ouvinte ou leitor o recebem segundo sua própria capacidade de acolhimento que, também ela, define-se por uma situação ao mesmo tempo limitada e aberta a um horizonte de mundo" (RICOEUR, 1994, p. 119), colocamos o espectador, como também, construtor de uma ficção periférica.

A partir dessa análise, pretende-se instaurar a ideia da ficção como onipresente, desde as camadas da ação efetiva e da recepção da narrativa até, logicamente, a narrativa ficcional melhor estruturada. Assim compreendemos que a noção de jogo, proposta por Guénoun (2012) como o ponto fulcral da necessidade do teatro em nossos tempos, é fundamentalmente ficcional. $E$ chegamos ao seguinte esquema de identificação: 
Figura 2 - Proposta de esquema para a identificação proposta pelo teatro contemporâneo

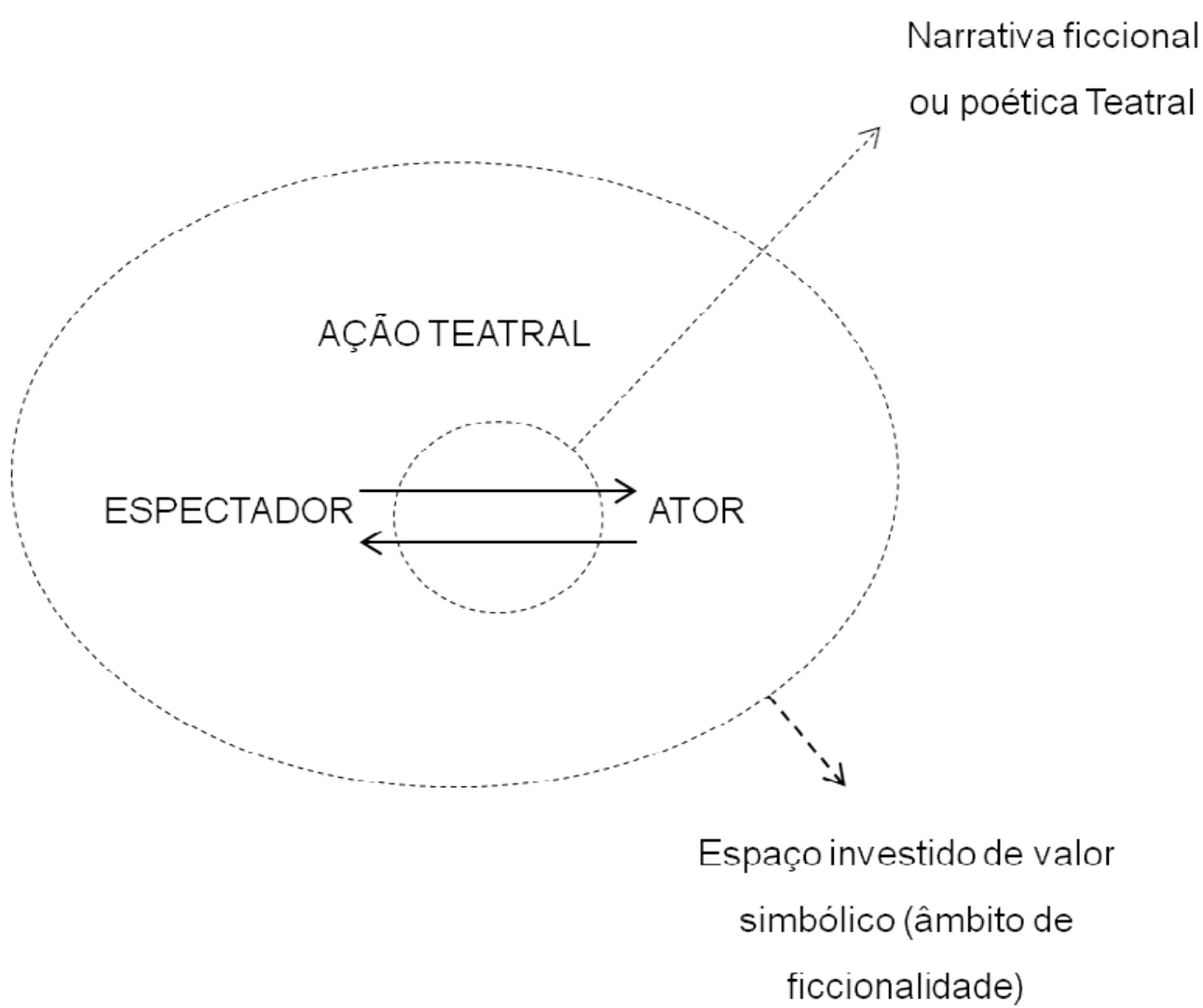

O personagem, enquanto entidade de ficção densa e elaborada, é nesse esquema mero coadjuvante, uma vez que se pensa a identificação espectador/ator como componente de uma ficção que caminha pela tangente, uma ficção que está diariamente presente na vida de todo ser humano. Ou seja, atores e espectadores se identificam enquanto seres ficcionalizadores, movidos por uma pulsão de ficção.

No esquema anterior, a poética teatral seria o intermediário desse reconhecimento, a lente que permite o deslindar da semelhança entre aquele que faz e aquele que assiste, e a ação teatral compreenderia todo esse processo, posto que - e é aí que ela se diferencia e ultrapassa o cinema e outras artes de âmbito não cênico - o teatro é o único que possibilita esse encontro imediato entre artista, obra e público, atingindo a um só golpe as três camadas miméticas de Paul Ricoeur. 
Além disso, se todo espectador é um jogador em potencial, ele o é por esse impulso rumo à ficção que o investe de ferramentas para adentrar a ação cênica ficcional. Se ainda hoje, rompida a ilusão cênica, há aqueles que movidos por uma necessidade de jogo vão ao teatro, é devido a sua pulsão de teatralidade. Assim, chega-se à conclusão de que assistir a teatro já não se trata de contemplar uma ficção exógena, mas inserir-se a si mesmo em um espaço em que toda situação é, como diria Sperber (2009a), uma situação-limite, pois já não existe a segurança que havia na época de Freud, o espectador já não está mais a salvo em sua poltrona, muitas vezes nem sequer está em uma poltrona. O espectador contemporâneo está em pleno aquecimento interno, prestes a dar vazão às suas pulsões, pronto para interferir em si, no outro e no mundo.

Toda essa proposta de identificação existe a partir da compreensão de que somos todos movidos por um impulso ficcional e que é essa pulsão de ficção que incide prazer sobre o encontro teatral, a partir do reconhecimento de que, se todos carregamos esse impulso de efabulação, a ordem da cena pode se alterar a qualquer momento, passando atores a espectadores e vice-versa. Nessa insegurança e, ao mesmo tempo, nessa confiança de que se pode fazer aquilo a que se assiste, que viria, então, a repousar a pulsão de teatralidade, que guarda a necessidade do teatro em nossos tempos. Se todos podemos, hoje, ser os personagens de Pirandello e dar-lhes vida - dando-Ihes materialidade cênica, não a partir da cópia fiel de suas tragédias, mas a partir da descoberta de que compartilhamos um mesmo traço estruturante: a ficção - então, o teatro é vivo.

\section{Referências bibliográficas}

FREUD, S. (1920) Além do princípio do prazer. In: Obras psicológicas completas: Edição Standard Brasileira. Rio de Janeiro: Imago, 1996

GUÉNOUN, D. O Teatro é necessário? Tradução de Fátima Saadi. São Paulo: Perspectiva, 2012.

PIRANDELLO, L. O humorismo. In: GUINSBURG, J. (org.). Do teatro no teatro. São Paulo: Perspectiva, 2009. p. 42-177. Seis personagens à procura de um autor. In: GUINSBURG, J. (org.). Do teatro no teatro. São Paulo: Perspectiva, 2009. p. 178-239. 
RICOEUR, P. Tempo e Narrativa, tomo 1. Tradução Constança Marcondes Cesar. Campinas, SP: Papirus, 1994.

SPERBER, S. F. Efabulação e pulsão de ficção. Remate de Males, n. 22, 2002. O diálogo entre mesmidade (identidade genética) e a ipseidade, responsável pela ética - ou, de uma alteridade constitutiva da responsabilidade na relação Eu-Tu. Revista Eletrônica Correlatio, n. 15, p. 5-15, 2009a.

Ficção e razão: uma retomada das formas simples. São Paulo: Hucitec, 2009b.

Recebido em 31/03/2016

Aprovado em 05/05/2016

Publicado em 30/06/2016 